\title{
INFERENCE ABOUT POPULATION ATTRIBUTABLE RISK FROM CROSS-SECTIONAL STUDIES
}

PREPARED UNDER THE AUSPICES OF

SIAM INSTITUTE FOR MATHEMATICS AND SOCIETY

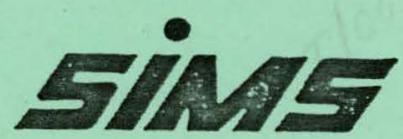

DIVISIONS OF BIOSTATISTICS AND

EPIDEMIOLOGY, \&

DEPARTMENT OF MATHEMATICAL STATISTICS

COLUMBIA UNIVERSITY

NEW YORK, NEW YORK

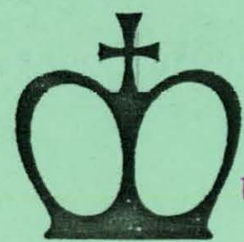




\section{DISCLAIMER}

This report was prepared as an account of work sponsored by an agency of the United States Government. Neither the United States Government nor any agency Thereof, nor any of their employees, makes any warranty, express or implied, or assumes any legal liability or responsibility for the accuracy, completeness, or usefulness of any information, apparatus, product, or process disclosed, or represents that its use would not infringe privately owned rights. Reference herein to any specific commercial product, process, or service by trade name, trademark, manufacturer, or otherwise does not necessarily constitute or imply its endorsement, recommendation, or favoring by the United States Government or any agency thereof. The views and opinions of authors expressed herein do not necessarily state or reflect those of the United States Government or any agency thereof. 


\section{DISCLAIMER}

Portions of this document may be illegible in electronic image products. Images are produced from the best available original document. 
INFERENCE ABOUT POPULATIION ATTRIBUTABLE

RISK FROM CROSS-SECTIONAL STUDIES

by

\author{
Joseph L: Fleiss \\ Division of Biostatistics \\ Columbia University School of Public Health \\ 600 West 168 Street \\ New York, N.Y. 10032
}

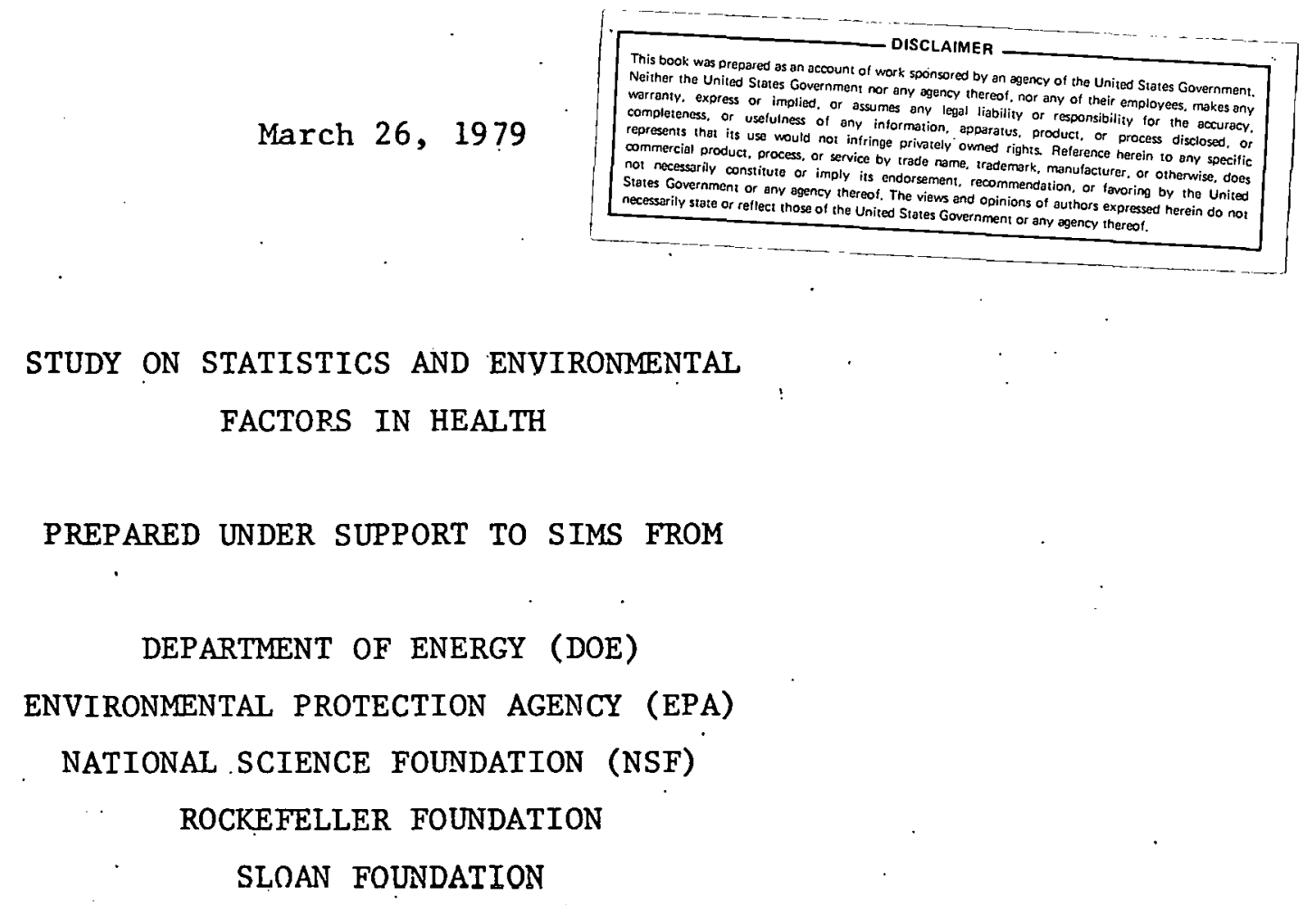
DIVISION OF BIOSTATISTICS
SCHOOL OF PUBLIC HEALTH
COLUMBIA UNIVERSITY
NEW YORK, NEW YORK

$\sum B$ 
- The population attributable risk (PAR) is defined as the fraction of all cases of a disease in a population due to exposure to a given risk factor: Letting $\mathbf{p}_{\mathbf{e}}$ denote the proportion of the population exposed to the risk factor and $R$ the relative risk, PAR may be defined (see 1 ) as

$$
\text { PAR }=\frac{P_{e^{(R-1)}}}{P_{e}(R-1)+1}
$$

Both Levin (i) and more recent students of PAR $(2 ; 3,4)$ have considered

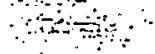

its estimation from case-control studies, when it may be assumed that the odds ratio closely approximates $R$ and that the rate of exposure in the control group closely approximates $P_{e}$ - Under these assumptions; Walter (3) derived an expression for the approximate standard exror of $\ln (1=\hat{P A R})$, where $\hat{P A R}$ denotes the estimated $P A R$ and in denotes the natural logarithm:

Little attention seems to have been paid to the problem of drawing inferences about PAR when the data are collected in cross-sectional surveys (such as those condacted by the National Center for Health Statistics) or as part of routine registration (such as the recording of number of live births and numbers of infant deaths in a city). Walter (5) considered this problem, and derived a complicated expression. for the standard error of PAR. Below; a relatively simple expression for the standard error of $\operatorname{In}(1-P \hat{A R})$ is presented.

Suppose the results of a cross-sectional study are tabulated as follows:

$$
\text { outcome Condition }
$$

$$
\text { Present }
$$

Exposed

Not Exposed

Total a

$c$

$a+c$
Absent

b

d

$b+d$
Total

$$
a+b
$$

$c+d$

n 
Because the estimate of $R$ is $a(c+d) / c(a+b)$ and the estimate of $P_{\theta}$ is $(a+b) / n$, the estimate of PAR for this kind of study becomes, after simplification;

$$
-\hat{P A R}=\frac{a d \cdot-b c}{(a+c)(c+d)}
$$

Using standard methods appropriate: for large samples (6), it may be shown that $\ln (1-P A R)$ is approximately normally distributed with mean $\ln (1-P A R)$ and standard error

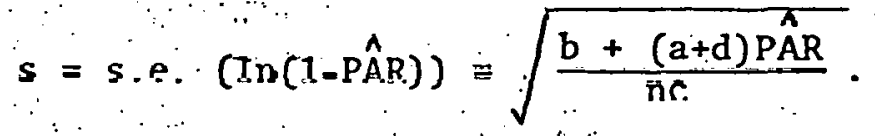

This formula is related to Walter's (see,"e.g., formula 2 in (7)) by $s=$ s.e. $(P \hat{R}) /(1-P A R)$. An approximate $95 \%$ confidence interval for PAR is $\left(P_{L}, P_{U}\right)$, where

$$
\mathrm{PAR}_{\mathrm{L}}=1-\exp (\ln (1-\mathrm{PAR})+1.96 \mathrm{~s})
$$

and

$$
\operatorname{PAR}_{U}=1-\exp (\ln (1-\mathrm{PAR})-1.96 \mathrm{~s})
$$

As an example, consider the following data from Erie County, li.Y. on levels of suspended particulates and mortality over a three year period (1959-1961) from cancer of the prostate (8).. The individuals were all white males aged 50-69 years residing in areas with a median family income between approximately $\$ 6,000$ and $\$ 12,00$ per year.

Moan Daily Level of Suspended Particulates
Died due to Prostatic Cancer
Alive, or Died of Other Causes

8,456
Total 8,465 34,919 
The estimated PAR is

$$
\hat{\mathrm{PAR}}=\frac{9 \times 34,897-8 ; 456 \times 22}{31 \times 34,919}=0,118,
$$

indicating that about $12 \%$ of deaths due to prostatic cancer in the study group may have been due. to residence in areas with high levels of suspended particulates.

The estimated standard error of $\ln \left(1-P A R^{\prime}\right)$ is

$$
s=\sqrt{\frac{8,456+(9+34,897) \cdot x \cdot 0: 118}{43,353 \times 22}}=0.115
$$

The lower $95 \%$ confidence bound on PAR is therefore

$$
\begin{aligned}
\operatorname{PAR}_{L} & =1-\exp (-0.126+1.96 \times 0.115) \\
& =1-1.105=-0.105,
\end{aligned}
$$

and the upper $95 \%$ bound is

$$
\begin{aligned}
\operatorname{PAR}_{U} & =1-\exp (-0.126-1.96 \times 0.115) \\
& =1-0.704=0.296
\end{aligned}
$$

The interval includes the value 0 , which is consistent with the absence of a statistically significant association between level of suspended particulates (as dichotomized here) and death due to prostatic cancer. Also consistent with the data, however, is the possibility that as many as $30 \%$ of all deaths due to prostatic cancer could. have been eliminated if daily levels of suspended particulates had been reduced below $100 \mathrm{\mu g} / \mathrm{m}^{3}$. 


\section{REFERENCES}

1. Levin M L: The occurrence of lung cancer in man. Acta Un Intern Cancer $9: 531-541,1953$

2. Cole P, Maclahon B: Attributable risk percent in case-control studies. Br J Prev Soc Med $25: 242-244,1971$

3. Walter S D: The distribution of Levin's measure of attributable risk. Biometrika $62: 371-374,1975$

4. Taylor $J \mathrm{~W}$ : Simple estimation of population attributable risk from casecontrol studies: An J Epidemiol 106:260, 1977

5. Walter $S \mathrm{D}$ - l'he estimation and interpretation of attxibutable risk in health rcscarchi Biometrics $32: 829=849,1976$

6. Rao $C$ R: Linear Statistical Inference and its Applications, 2nd Ed. New York, Wìley, 1973

7. Walter $\mathrm{D}$ : Calculation of attributable tisks from epidemiological data. Intern J Epidemiol $7: 175-182,1978$

8: Winkelstein W; Kantor S: Prostatic cancer: Relationship to suspended particulate air pollution. Amer J Pub Hith 59:1134-1138, 1969 